\title{
THE
}

$12-2011$

\section{Concept Tests for a New Wire Flying Vehicle Designed to Achieve High Horizontal Resolution Profiling in Deep Water}

\author{
Chris Roman \\ University of Rhode Island, croman2@uri.edu \\ Dave Hebert \\ University of Rhode Island, davidhebert@uri.edu
}

Follow this and additional works at: https://digitalcommons.uri.edu/gsofacpubs

Part of the Ocean Engineering Commons, Oceanography Commons, and the Robotics Commons

Terms of Use

All rights reserved under copyright.

\section{Citation/Publisher Attribution}

Roman, Chris, Dave Hebert, 2011: Concept Tests for a New Wire Flying Vehicle Designed to Achieve High Horizontal Resolution Profiling in Deep Water. J. Atmos. Oceanic Technol., 28, 1657-1671.

Available at: http://dx.doi.org/10.1175/JTECH-D-10-05040.1

This Article is brought to you for free and open access by the Graduate School of Oceanography at DigitalCommons@URI. It has been accepted for inclusion in Graduate School of Oceanography Faculty Publications by an authorized administrator of DigitalCommons@URI. For more information, please contact digitalcommons-group@uri.edu. 


\title{
Concept Tests for a New Wire Flying Vehicle Designed to Achieve High Horizontal Resolution Profiling in Deep Water
}

\author{
Chris Roman AND DAVe HeBerT* \\ Graduate School of Oceanography, University of Rhode Island, Narragansett, Rhode Island
}

(Manuscript received 6 December 2010, in final form 15 August 2011)

\begin{abstract}
Efficiently profiling the water column to achieve both high vertical and horizontal resolution from a moving vessel in deep water is difficult. Current solutions, such as CTD tow-yos, moving vessel profilers, and undulating tow bodies, are limited by ship speed or water depth. As a consequence, it is difficult to obtain oceanographic sections with sufficient resolution to identify many relevant scales over the deeper sections of the water column. This paper presents a new concept for a profiling vehicle that slides up and down a towed wire in a controlled manner using the lift created by wing foils. The wings provide a novel low-power method of propulsion along the cable by using the free stream velocity of the wire moving through the water in similar fashion to a sailboat sailing up wind. Scale model tests show a wide range of achievable profiling glide slopes for tow cable angles between vertical and $45^{\circ}$, and effective isolation of cable strum vibration from the towed vehicle body. The concept is not depth limited and will offer two-dimensional resolution that meets or exceeds current undulating tow bodies over the full water column. Additionally, this system could be used simultaneously with many other deep towed instrument packages to produce complementary datasets.
\end{abstract}

\section{Introduction}

Ocean processes on horizontal scales from $50 \mathrm{~km}$ to $10 \mathrm{~m}$ are energetic, largely uncharted, and have particular societal relevance. Brewer and Moore (2001) identified a critical need to understand these processes where stirring and mixing regulate ocean thermocline structure, chemical distributions, and influence biological processes directly. The next advances in the field will almost certainly be in the submesoscale (kilometers and smaller), given their importance to ocean processes. As such, it is necessary to develop the tools to observe both the vertical and horizontal spatial structure of the water column, especially well away from the sea surface, and find linkages to the various processes acting within the water column or on the seafloor below. Two specific examples, among many, that have motivated this vehicle concept are the mechanisms of deep-ocean mixing and

* Current affiliation: Department of Fisheries and Oceans, Bedford Institute of Oceanography, Dartmouth, Nova Scotia, Canada.

Corresponding author address: Chris Roman, University of Rhode Island, 215 South Ferry Rd, Narragansett, RI 02882.

E-mail: cnr@gso.uri.edu the structure of hydrothermal plume signals in areas of active seafloor venting.

Recent measurements of turbulent dissipation rates in the deep ocean have shown enhanced mixing several hundred meters above rough topography (Polzin et al. 1997). They concluded that such patterns in vertical mixing imply that abyssal circulations have complex spatial structures that are linked to the underlying bathymetry. Using traditional microstructure instruments to measure turbulent dissipation rates in the deep ocean is very difficult and time consuming because it requires using a free-fall profiler over the full water depth. Thus, it takes several hours to obtain a single profile and the exact location of the profiler relative to the bottom topography is not known. However, these turbulent patches produce overturns in the density structure that are related to mixing rates (Crawford 1986; Dillon 1982). Consequently, a vertically profiling CTD can be used to detect these overturns and estimate the turbulent dissipation rates if ship motion can be removed from the measurements. Towed undulating CTDs have also been used to get similar estimates of mixing rates in shallow water if the glide path is sufficiently steep (Ullman et al. 2003). The trajectory steepness requirement for estimates of overturning scales arises from the need to avoid aliasing horizontal structures into the along-trajectory density 
$\mathrm{T}$
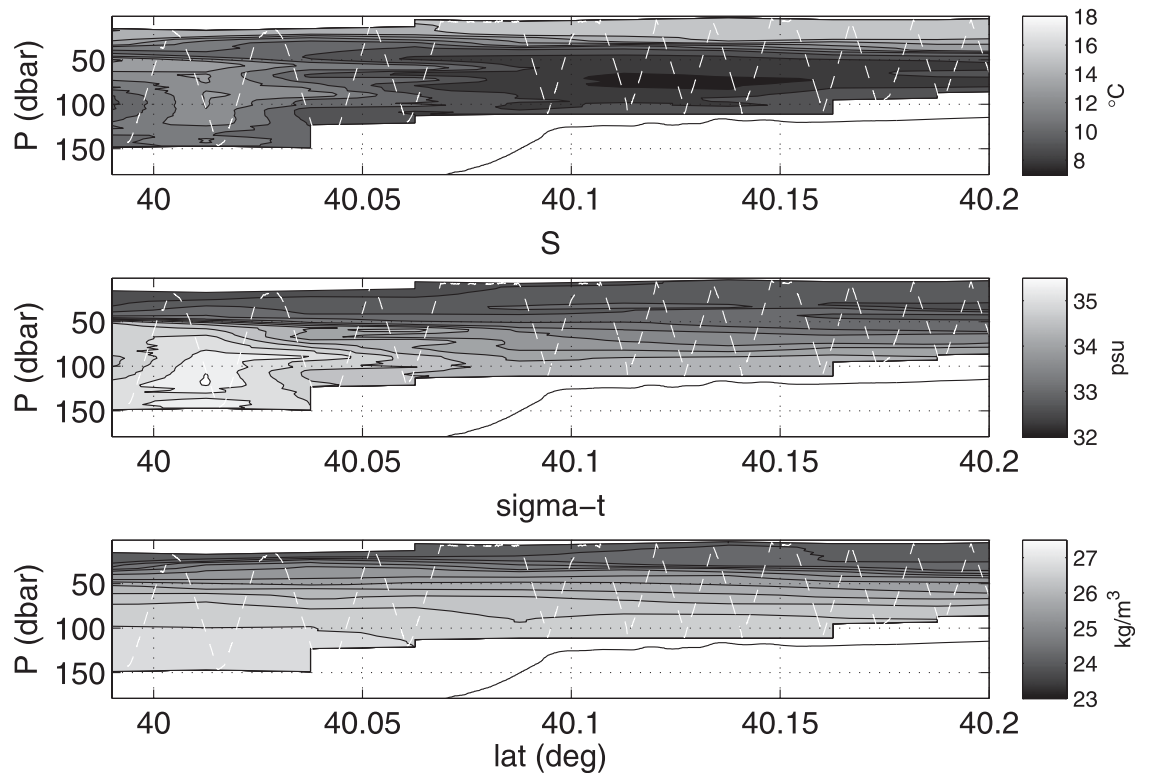

FIG. 1. Scanfish section of the shelfbreak front south of Rhode Island. Towed at $6 \mathrm{kt}$, the vertical to horizontal sampling is nominally $1 / 8$.

observations. For the horizontal structure from internal waves the trajectory glide slope, vertical over horizontal, must be steeper than approximately 0.2 (Ullman et al. 2003) to apply overturn detection methods. In frontal regions with significant horizontal gradients, trajectories may need to be significantly steeper to use this methodology. The actual steepness needed depends on the ratio of the horizontal to vertical density gradients in the region of interest; however, it is clear that in this case the steeper the trajectory, the better.

Recent work (Klymak and Moum 2007) has also demonstrated that turbulent mixing rates can be obtained from isopycnal slope spectra for wavenumbers out to greater than $1 / 100 \mathrm{~m}$. To obtain the isopycnal slope spectra, it is necessary to measure both the vertical and horizontal temperature and salinity structure with as high as possible resolution. Making these measurements from a towed sampling platform also requires steep trajectories within specific depth bands in order to resolve the necessary horizontal scales. As evident from a section conducted at the shelfbreak front south of Rhode Island (Fig. 1), the spacing between adjacent profiles in a Scanfish survey is between 750 and $1000 \mathrm{~m}$ at middepth (with a trajectory slope of $0.1-0.2$ ). To operate these towed bodies, the vessel must maintain a certain speed to provide sufficient lift for the vehicles. Thus, it is only possible to obtain higher horizontal resolution data by limiting the vertical excursion. In frontal regions such as the shelfbreak front, there are important hydrographic features such as filaments and intrusions that cannot be resolved adequately with these instruments. In the past, to obtain the highest possible horizontal resolution, tow-yos of the CTD were conducted. This, however, limits the vessel's speed to a couple of knots in order to keep the drag on the package low, and the ship's winch must be continuously operated by a crew member, making the whole operation fairly inefficient and labor intensive.

In a different context, resolving the structure of hydrothermal plumes in the water column while simultaneously mapping the bottom topography to identify active venting systems is challenging. Past studies, in water depths typically deeper than $2000 \mathrm{~m}$, have often started by mapping the broad bathymetry using ship-based multibeam, followed by tow-yo, CTD surveys (D'Asaro et al. 1994), or by fixing a few additional sampling units on a tow cable (Baker and German 2004). Autonomous underwater vehicles (AUVs) are also used for deep-vent studies, but towed systems are better suited to provide the broader survey and identification of initial AUV starting points to within several kilometers of suspected vent sites (German et al. 2008). Trade-offs still remain for collecting bathymetric and both vertical and horizontal water column data over extents of tens to hundreds of kilometers along a ridge in an efficient and detailed manner (German et al. 1998; Langmuir et al. 2004). Hydrothermal plumes will rise and spread laterally hundreds of meters above the typical $50 \mathrm{~m}$ or closer mapping altitudes for towed and AUV seafloor mapping systems. The mapping systems 
also need to be towed or flown at nominally constant altitudes, making it infeasible to simultaneously profile in the plumes and collect bathymetry data. Decoupling the seafloor mapping from the water column plume sampling would allow better and simultaneous sampling of the related processes.

The common limitation in these problems is the inability to profile deep waters with sufficient horizontal and vertical resolution to capture many of the relevant spatial scales. This suggests the need for a system that can achieve high, greater than 0.25 , glide slopes over any desired part of the water column from top to bottom. Additionally, there would be a significant operational advantage for a system that is able to simultaneously collect water column data and map the seabed. Beyond the traditional CTD tow-yo surveys, options for achieving this type of work are limited. Numerous avenues do exist, however, for shallow profiling to a few hundred meters depth from a moving vessel and deep-water profiling at static locations. These are reviewed here with consideration for their applicability to the deep ocean.

\section{a. Undulating tow bodies}

Commercially available undulating tow bodies, such as the Chelsea SeaSoar (Allen et al. 2002), EIVA Scanfish, and Sea Sciences Acrobat, can be used to profile the surface waters up to 500-m depth. These vehicles use wing foils to control their depth and can be towed at ship speeds up to $8 \mathrm{kt}$. The limitation of these vehicles, however, is the attached tow cable fixed to the body. The cable is pulled up and down through the water as the vehicle flies. The large drag forces produced by the cable limit the achievable glides slope to 0.25 and the maximum depth at which they can work. Faired cables can help reduce the cable drag, but it is not possible to extend the towed undulating vehicle concept to full ocean depth.

\section{b. Moving vessel profilers}

The Brooke Ocean moving vessel profiler (MVP) system (Herman et al. 1998; Furlong et al. 2006) and the smaller Oceanscience Underway CTD (Rudnick and Klinke 2007) are capable of vertical profiling and bottom sampling in waters up to 5000-m depth. These systems use a free-falling sensor that is repeatedly dropped, at speeds up to $4 \mathrm{~m} \mathrm{~s}^{-1}$, and reeled back to a moving ship by a specialized winch. These systems are useful for repeated sampling but are limited by the cycle time between deployments, which dictates the spacing between vertical casts. Additionally, the systems are not able to profile within a deep depth window without recovering the profiler to the surface between casts. Although the full profiles may be useful for some applications, the added time limits the sampling density for applications such as plume studies, where only the lower portion of the water column is of interest. As an example, the advertised cycle time for the MVP profiling moving at $3 \mathrm{kt}$ to $2500 \mathrm{~m}$ is $40 \mathrm{~min}$ and would result in a $3.6-\mathrm{km}$ spacing between casts. Profiling only the bottom $360 \mathrm{~m}$ of the water column with a vehicle capable of glide slopes of 1.0 would result in 10 times the horizontal resolution at depth.

\section{c. Cable clamped sensors}

For deep-sea hydrothermal plume studies small datalogging devices called miniature autonomous plume recorders (MAPRs) have been developed (Baker and Milburn 1997). The small MAPRs units, packaged as 8.1-cm-diameter and 41-cm-long cylinders, can be bolted to the tow cable and have been used in conjunction with towed side-scan sonar systems flown at a fixed height above the seafloor. Used in this manner, MAPRs primarily produce horizontal sampling paths in the water column above deep-sea vent areas. Although they have been very successful in vent prospecting, their main drawback is that they are fixed to the cable at set spacings and the vertical resolution is still very coarse compared to what active profiling would provide. The fixed spacing, in comparison to a controllable moving profiler, also requires recovery of the cable to adjust the position of the sensors.

For CTD measurements only the Analoge Digitale Meßsysteme (ADM) towed CTD chain uses small inductively coupled sensors and a specialized cable (Sellschopp 1997). The sensors bolt to the cable but do not require a direct electrical connection. Up to 255 sensors can be fixed on a single cable that is $500 \mathrm{~m}$ in length. This system provides discrete vertical resolution and continuous horizontal sampling. The vertical resolution is set by the discrete spacing between the sensors, as determined by the tow depth and the number of sensors. The overall specialty of the system requires a dedicated coated cable and winch, and each of the individual sensors will be low cost, small, and low power.

\section{d. Moored profilers}

For sampling in a fixed location, the moored profiler (Doherty et al. 1999; Morrison et al. 2000), which consists of a vehicle that repeatedly climbs a fixed wire using a wheel drive, has been very successful. The adaption of the profiler vehicle to climb a towed wire, however, is not a viable option for a ship-based towed system. The profilers are designed for long-duration and low-power operation and would lack the power required to climb a cable against a significant amount of flow.

A second novel concept for stationary profiling is the SeaHorse wave action profiler, which is also produced by Brooke Ocean Technology (Fowler et al. 1997). The SeaHorse profiler uses wave action and a mechanism for 
successively grasping and releasing a vertical buoy cable to produce a profiling motion. As designed, the SeaHorse rides on a static mooring deployed at a fixed location. Because the vehicle is designed for the static environment the body shape is not streamlined. This system has not been adapted for towed use and its would-be performance is unknown.

\section{e. Autonomous systems}

Profiling with autonomous and Lagrangian platforms has become increasingly useful for oceanographic water column data collection (Dickey et al. 2008). Free-swimming gliders (Eriksen et al. 2001; Webb et al. 2001) can profile at steep angles for long durations and cover thousands of kilometers of open ocean. However, their limited forward speed makes them more appropriate for broaderscale long-duration studies rather than creating synoptic sections of the water column over hourly or daily time scales. Autonomous underwater vehicles can also be used for profiling and ballasted to allow steep dive trajectories. These systems are decoupled from the support vessel, but do have the inherent risks associated with untethered deployments. They may also require acoustic tracking from a support ship to provide position information when working in the mid-water column in between trips to the surface where GPS is available (Kinsey et al. 2006).

\section{The wire flying vehicle}

The presented design concept for a gliding vehicle that is able to fly up and down a towed cable using low-power propulsion has several advantages compared with the previously mentioned systems. Figure 2 shows an overall view of the wire flyer system, where several vehicles move along a single tow cable held in tension by a heavy depressor weight. Each flying vehicle uses wing foils to produce lift from the free streamflow of water past the cable. By controlling the wing angles, the vehicle can move up and down the cable, which slides through the vehicle on rolling mounts. Each flyer vehicle will carry a CTD or other sensors to collect data while either climbing the tow cable or descending using downward wing angles. Because of the differing efficiencies of climb and descent, the actual path through the water will be the asymmetric sawtooth pattern shown. The upward performance of the vehicle will decrease as the cable angle tends away from vertical and the along cable component of foil lift becomes less effective. The heading stability of the vehicle is provided by the trailing tail fin, and the overall streamlined body shape provides lateral stiffness in the water to help isolate the cable strum vibration.

For the above-mentioned applications of deep mixing and vent mapping the proposed vehicle should be

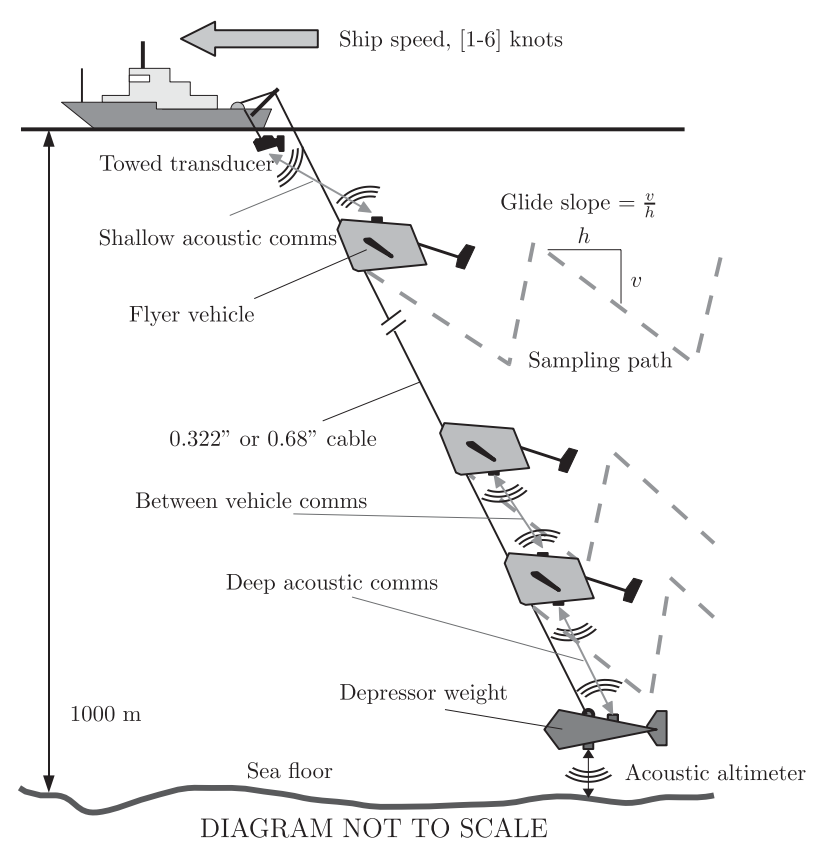

FIG. 2. System diagram showing both shallow and deep operations. Each flyer is given a desired sampling pattern and depth window to work in. The depressor weight keeps tension in the cable and provides altitude information to the topside winch operator. Several possible pathways for acoustic modem communications could be available between the vessel or depressor weight.

capable of profiling a vertical region of $500 \mathrm{~m}$ in the lower portion of the water column down to full ocean depths on a $0.322^{\prime \prime}$ or $0.680^{\prime \prime}$ oceanographic cable. To be consistent with standard CTD operations and sensor response times, the maximum vertical speed of the profiler should be on the order of $1.0 \mathrm{~m} \mathrm{~s}^{-1}$. There is no lower limit for the vertical profiling speed, because the vehicle will be capable of controlled level flight at a prescribed depth. Given the drag on the oceanographic cable the horizontal speed of the towed system is anticipated to be in the range between 1.0 and $3.0 \mathrm{~m} \mathrm{~s}^{-1}$. These criteria would result in a horizontal spacing between repeated profiles of 1000 and $3000 \mathrm{~m}$, respectively, with a cycle time of $15 \mathrm{~min}$. The required average glide slopes would need to be between 1.0 and 0.3 .

Initial predictions and tests suggest that the vehicles can achieve these glide slopes and either meet or exceed those of existing undulating tow bodies. The system will offer flexible sample patterns over any portion of the full water column, and it is not directly limited by depth. Similar to towed undulating bodies and free-falling profilers, the vehicles will also be decoupled from direct ship heave and will produce smooth controllable trajectories. Used in conjunction with other towed systems, such as a deep-tow side-scan sonar serving as the depressor weight, the flyers 

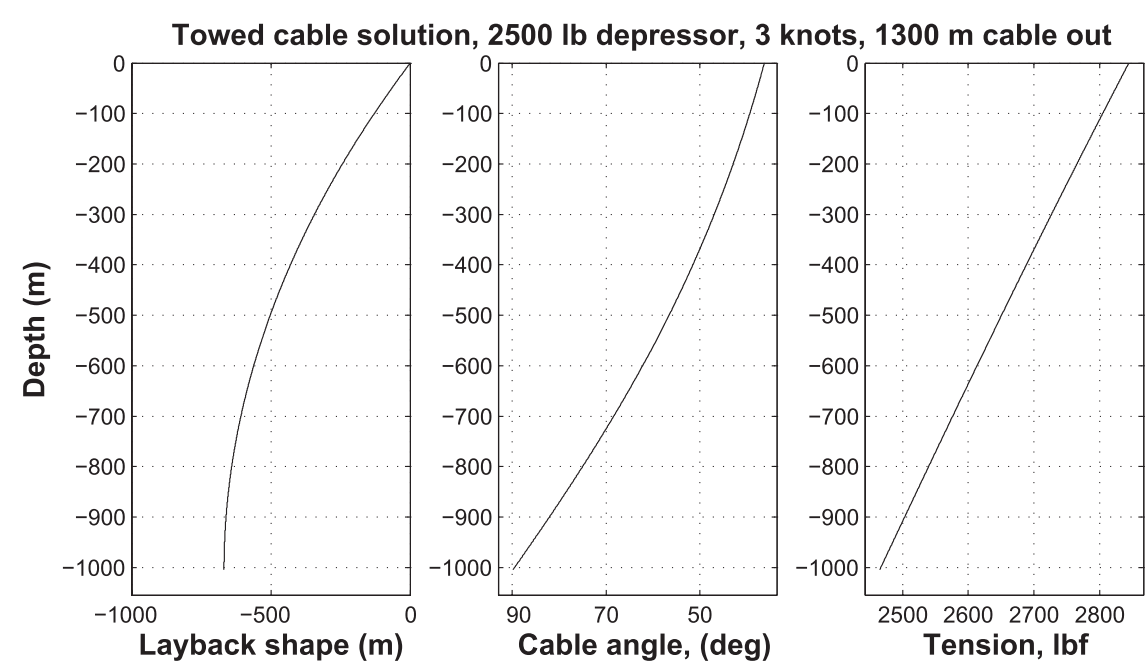

FIG. 3. Tow cable shape, angle, and tension for $0.322^{\prime \prime}$ cable towing a $2500-1 b$ depressor weight at $3 \mathrm{kt}$. Note the cable tends more vertical at deeper depths and the shallowest angle is near the surface.

could collect a complementary dataset of water column measurements decoupled from the tow cable management that is needed to operate the sonar near the bottom.

\section{Tow cable behavior}

Because the wire flyer vehicles will ride along a towed cable, it is necessary to estimate the basic behavior of a deep-sea towed cable. The predictions presented here were done using the Woods Hole Oceanographic Institution (WHOI) Cable (Gobat and Grosenbaugh 2000), a software package that is used to analyze towed cables and complex moorings. Figure 3 shows a sample solution for cable shape, angle, and tension as a function of depth. The dominant parameters are the cable diameter and weight per length, ship speed, length of cable out, and weight of the tow body depressor at the end. For a heavy depressor weight the cable will tend to be more vertical at the bitter end, while the tension increases linearly from bottom to top. For the flyer concept specifically, we are interested in the cable angle as a function of the cable out, ship speed, and depressor weight mass. For a specific range of operating conditions it is possible to summarize the range of anticipated cable angles.

The cable angles for various ship speeds and depressor weights were examined for some representative towing situations (Fig. 4). In each case the depressor was modeled as a low drag, $C_{D}=0.25,30$-cm-diameter streamlined body of varying length. For shallow depths, less than $250 \mathrm{~m}$, a heavy low-drag depressor allows for ship speeds approaching $6 \mathrm{kt}$ with cable angles greater than $55^{\circ}$ (Fig. $4 \mathrm{a}$ ). Tows down to $2000 \mathrm{~m}$ are obviously more restrictive, but still allow cable angles greater than $60^{\circ}$ for speeds up to $3 \mathrm{kt}$ (Fig. 4b). For deep tows to $5000 \mathrm{~m}$ using a $0.68^{\prime \prime}$ cable, angles greater than $60^{\circ}$ are possible below $4000 \mathrm{~m}$ at tow speeds up to $3 \mathrm{kt}$ (Fig. 4c). These tows are typical for deep towed sonar systems such as the DSL-120 and IMI-30, operated by the Hawaii Mapping Research Group (HMRG), which are designed to be towed at 1 and $2 \mathrm{kt}$, respectively. The angles closer to the bottom of the cable are shown to be representative of situations where the vehicle is profiling the deeper region of the water column near the bottom. These angles will, in general, be greater than the angles farther up the cable. For example, a vehicle working below $750 \mathrm{~m}$ in the situation shown in Fig. 3 would see more vertical angles greater than $70^{\circ}$, where the angle at $500 \mathrm{~m}$ is closer to $55^{\circ}$. Creating steeper cable angles by using heavier depressor weights for a given ship speed is eventually limited by the safe working tension in the cable. This will ultimately impose a limit on the profiling rate of the vehicle as the angle becomes too shallow to climb. Maintaining cable angles steeper than approximately $45^{\circ}$ will need to be factored into the choice of survey speed, depth, and depressor weight.

Additionally, these cable simulations suggest that there will be little, if any, change in the cable shape when considering the additional forces applied to the cable by the flyer vehicles themselves. This can be evaluated in WHOI Cable by placing discrete forces on the cable at specific locations and checking for changes in the cable angle or shape at that point. The magnitudes of these forces were estimated using the performance predictions described in section 5 .

The second dominant behavior of a towed cable is strum, or the vibration caused by vortex shedding in the downstream wake of the cable. For the flow regime of ship-towed cables the Reynolds number will be on the 
(a)

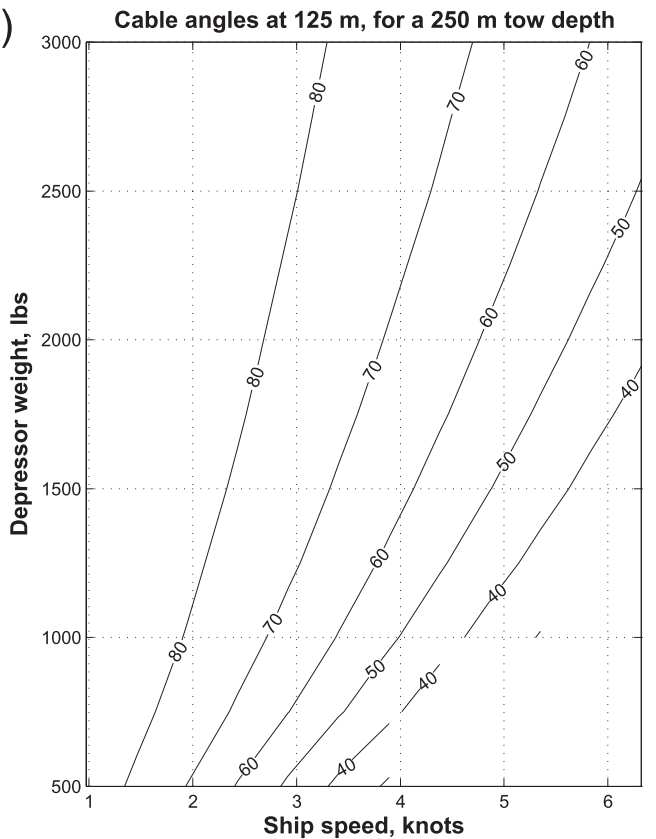

(b)

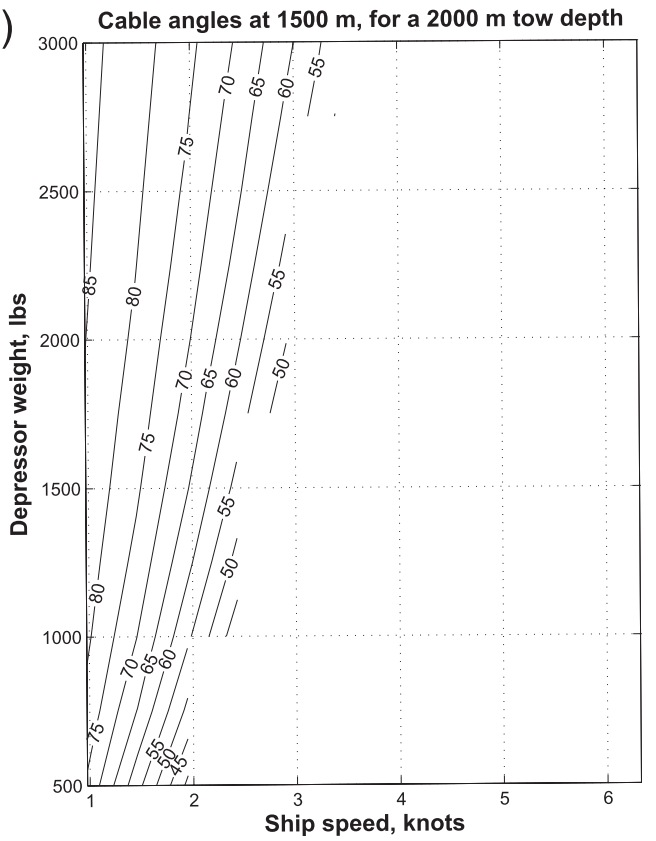

(c)

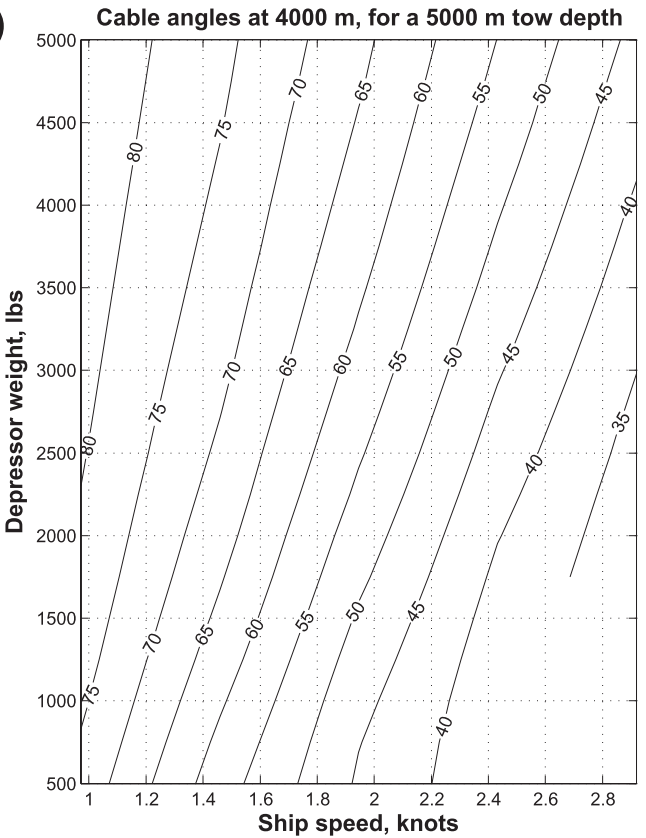

FIG. 4. Sample plots showing the anticipated cable angles, relative to horizontal, at various ship speeds and depressor weights for standard $0.322^{\prime \prime}$ and $0.68^{\prime \prime}$ wire. (a) Cable angles at $125-\mathrm{m}$ depth for a shallow tow with the depressor depth at $250 \mathrm{~m}$. (b) Cable angles at 1500-m depth for a 2000-m depressor depth. (c) Cable angles at 4000-m depth for $0.68^{\prime \prime}$ wire with a depressor depth of $5000 \mathrm{~m}$. Note that the data from some high-speed and low-weight solutions is missing where WHOI Cable was unable to converge on a solution.

order of $10^{4}$ and in the transition region between laminar and turbulent flow. The Strouhal number, which relates the vortex-shedding frequency to the cable diameter and flow speed for a cylinder in cross flow, in this regime is approximately 0.2 (Blevins 1977). This indicates that the expected vibration frequency for the cable will be in the range between 5 and $20 \mathrm{~Hz}$. The amplitude of the vibration is typically on the order of several cable diameters. For the flyer concept we need to be concerned with the transmission of the vibration to the vehicle on the wire. Vibrations of the vehicle will detrimentally increase the drag and limit the achievable performance. Section 


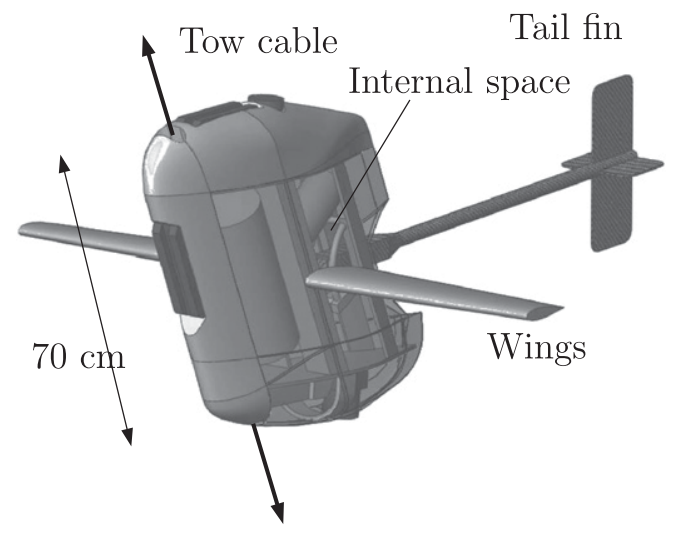

(a)

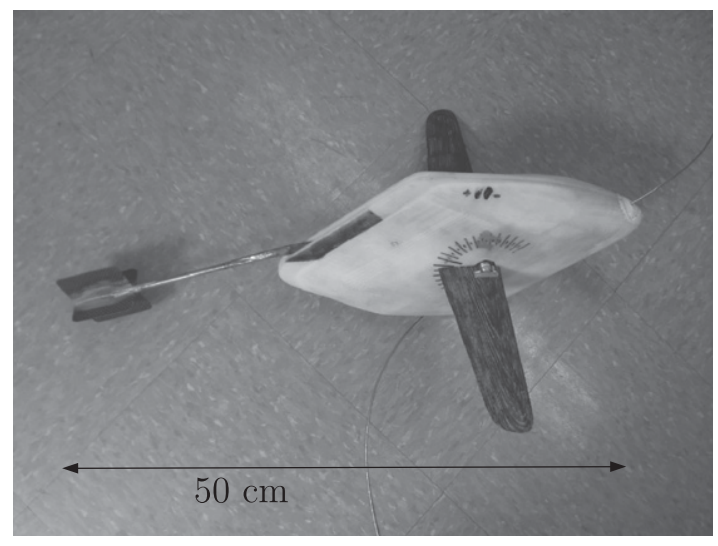

(b)

FIG. 5. (a) Concept model of a 1000-m rated flyer vehicle showing the major components. (b) Picture of the scale model used for the tow-tank tests with the $3-1$ aspect ratio wings and short tail fin attached.

6 addresses isolation of the strum and shows initial test results.

\section{System description}

An initial concept drawing for a flyer vehicle and the model used for scale testing are shown in Fig. 5. The complete vehicle will be a free-flooding design consisting of sealed pressure housings and components supported by a frame structure, all inside a faired plastic shell. Overall, the vehicles will have slight positive buoyancy and use syntactic foam to offset the weight of the mechanical parts. This concept study focused on the initial design considerations for the body and wings, tail fin, and cable attachment mechanism. The internal specifics of a complete design will be worked out in future efforts and the overall performance of the system is dictated by these three major considerations discussed here.

\section{a. Body and wings}

The general shape of the body is designed to achieve low drag and is based on the symmetric National Advisory Committee for Aeronautics (NACA) 0022 (Abbott and Doenhoff 1959) airfoil shape. The shape is used in the horizontal plane and extruded at an angle relative to vertical. The swept look accounts for a cable angle persistently varying between $80^{\circ}$ and $50^{\circ}$ and optimizes the shape for climbing up an inclined cable. Digital computeraided design (CAD) models of body shapes have been evaluated using the SolidWorks Flow Simulation software package to quantify the variation in body drag as a function of the apparent flow direction. Figure 6 shows a simplified sample body with a minimum body drag occurring at an incident flow angle above the horizontal. At this angle the body presents a more slender shape to the incoming flow.
The wings are based on the NACA 0012 (Abbott and Doenhoff 1959) airfoil cross section extruded to aspect ratios, defined by the base to tip length divided by the chord length, between 2 and 4 . The wing designs attempt to maximize lift and minimize induced drag. This generally involves trade-offs between the specific foil cross section, aspect ratio, and total plan area (Abbott and Doenhoff 1959). Higher aspect ratio foils are beneficial for lift up to a point of diminishing returns in terms of relative gain, stall behavior, and general practicality. Overall, a more compact, lower aspect wing of comparable performance will make the vehicle smaller for easier deck handling and produce a lower bending torque at the base of the rotating mounting shafts. In a full-scale vehicle the wing angle will be controlled using a servo motor and gear train mechanism. An active computer control system will be able to adjust the wing angles to achieve the desired profiling performance even as the cable angle varies with depth.

\section{b. Tail fin}

Model testing has indicated that a tail fin is required for the vehicle to maintain passive heading stability while being towed from near the leading edge of the body. In this situation the relative position of the body's center of lift and center of mass are important. Without the tail fin the center of lift is either near or in front of the center of gravity, which is an unstable aerodynamic configuration that results in the vehicle oscillating in heading and wanting to turn away from the cable. Introducing the tail fin moves the overall center of lift behind the center of gravity and into a stable arrangement that allows the vehicle to maintain a stable direction in the presence of perturbations at the tow point. To account for the vertical change in apparent velocity 


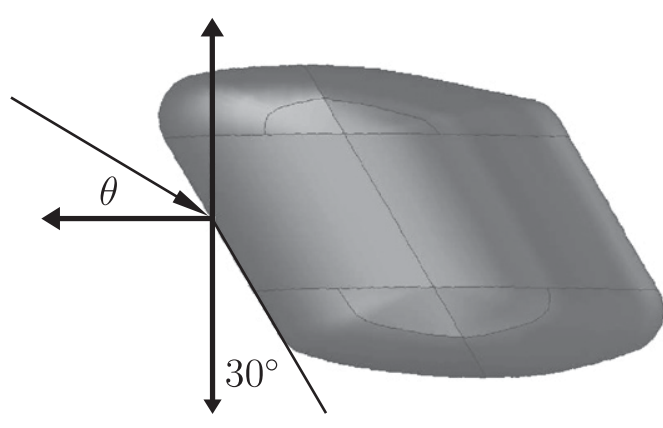

(a) CAD model

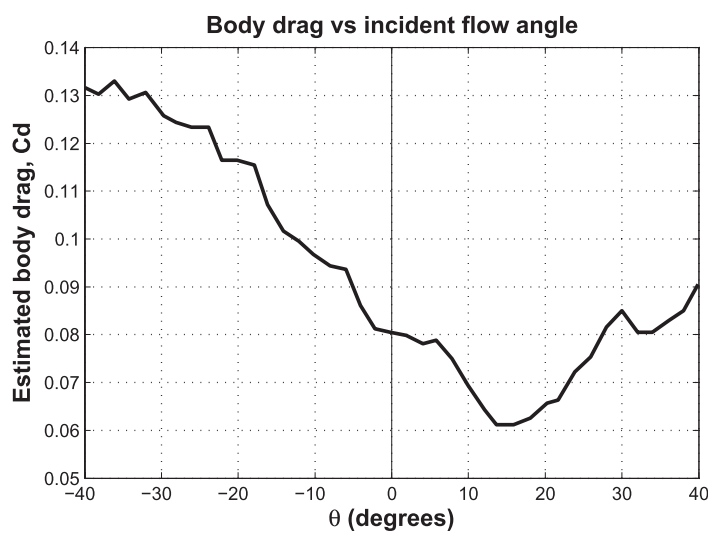

(b) Drag plot

FIG. 6. (a) A sample SolidWorks CAD model that was used to estimate the drag at various apparent incoming flow angles $\theta$ to a body. The leading edge of the model is swept back $30^{\circ}$ from vertical. (b) Plot of the estimated drag coefficient at different flow angles to the body.

to the vehicle as it flies either up or down the cable, the tail fin will passively rotate in the vertical plane on a pivot. This allows the tail to maintain alignment with the incoming flow and minimize drag. The main considerations for the tail design are its length, weight, and arc of travel. For passive motion it should be essentially neutrally buoyant and allowed to rotate in line with the anticipated range of incoming flow angles. To minimize drag it should be as small as possible while still maintaining heading stability.

\section{c. Cable attachment}

The attachment mechanism to the cable must be secure but allow the vehicle to slide easily along the cable. The sliding resistance should be minimized to not create an additional retarding force opposing the vehicle's motion. This will most likely be done with rolling pulley wheels that grasp the cable on the front and sides. The attachment mechanism must also be able to isolate the vehicle body from the cable strum vibrations. Vibrations transferred to the vehicle would increase the overall body drag. Vibrations would also be detrimental to the basic mechanical structure of the vehicle and any electrical components. Initial isolation concepts include a pulley capture assembly that both grabs the cable and is allowed to move laterally inside the vehicle with cable vibrations. The assembly could be either mounted on spring-loaded slides or attached to the end of a flexible beam. By tuning the stiffness and travel of the slides or beam it is possible to let the cable vibrate as it passes through the vehicle without the vibration coupling to the entire vehicle body. This allows the vehicle to maintain a smooth flight on the vibrating cable. Scale model test results demonstrating this vibration isolation are given in section 6 .

\section{Performance predictions}

The estimated performance of the vehicle can be modeled starting with the free-body diagram in Fig. 7a. The relevant forces acting on the vehicle are the components of wing lift, wing drag, and body drag along the cable direction. Using the set of initial parameters shown in Table 1 for an anticipated full-sized vehicle the predicted glide slopes can be calculated for a range of cable angles.

When the vehicle is moving the apparent flow velocity $v_{a}$ and incoming flow angle $\theta$ can be determined using the ship speed $v_{s}$, cable angle $\phi$, and along-cable velocity $v_{c}$ as

$$
\theta=\tan ^{-1}\left[\frac{v_{c} \sin (\phi)}{v_{s}+v_{c} \cos (\phi)}\right],
$$

and

$$
v_{a}=\left\{\left[v_{s}+v_{c} \cos (\phi)\right]^{2}+\left[v_{c} \sin (\phi)\right]^{2}\right\}^{1 / 2} .
$$

Knowing the apparent velocity, the total wing lift $L_{w}$ and drag $D_{w}$, and their respective along-cable components $L_{w c}$ and $D_{w c}$, can be calculated using the standard quadratic lift and drag equations

$$
\begin{aligned}
& L_{w}=\frac{1}{2} \rho A_{w} v_{a}^{2} C_{l}, \quad L_{w c}=L_{w} \sin (\phi-\theta), \\
& D_{w}=\frac{1}{2} \rho A_{w} v_{a}^{2} C_{d}, \quad D_{w c}=D_{w} \cos (\phi-\theta) .
\end{aligned}
$$

Because the wing angle $\omega$ will be controlled in real time, the lift coefficient $C_{l}$ and drag $C_{d}$ can be estimated from the existing airfoil data, assuming that the wings will be trimmed to achieve a specific angle of attack (Abbott 


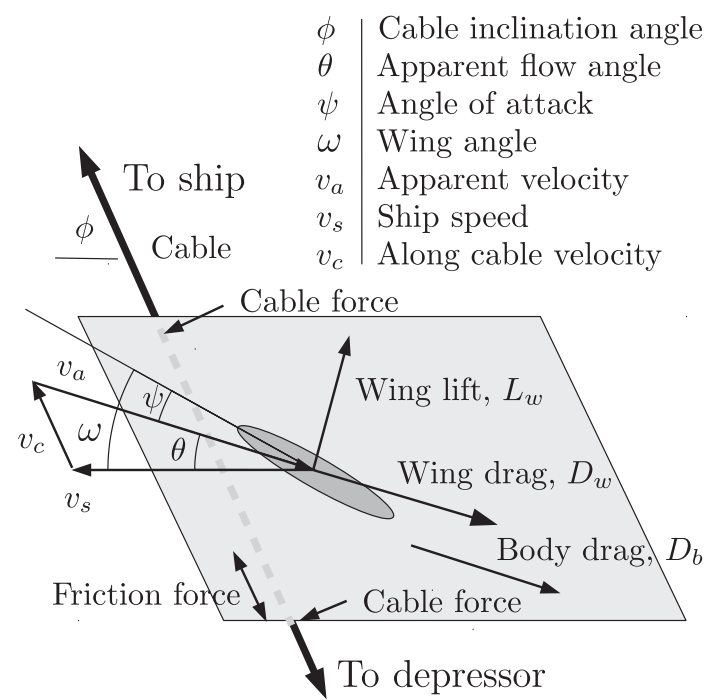

(a) Free body diagram

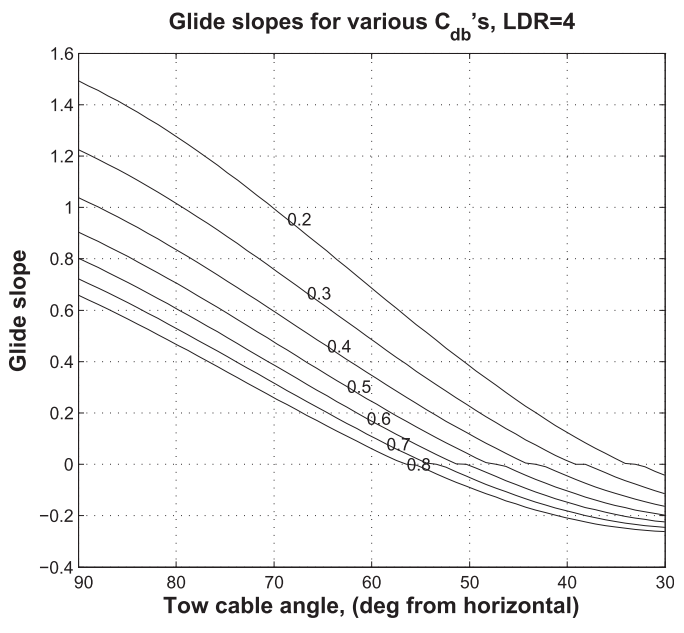

(b) Estimated glide slopes

FIG. 7. (a) A simple free-body diagram showing the relevant velocities and forces acting on the flyer. (b) Performance estimates for a full-scaled system using the assumed parameters in Table 1. Curves are shown for differing body drag coefficients using a constant wing lift-to-drag ratio.

and Doenhoff 1959). For the drag force acting on the body we consider the body drag as the sum of the skin friction drag $D_{b s}$ and the form drag $D_{b f}$. The components of these forces along the cable $D_{b s c}$ and $D_{b f c}$, respectively, can be calculated with

$$
D_{b s}=\frac{1}{2} \rho\left(A_{w}+A_{b s}\right) v_{a}^{2} C_{d s}, \quad D_{b s c}=D_{b s} \cos (\phi-\theta),
$$

$$
D_{b f}=\frac{1}{2} \rho A_{b p} v_{a}^{2} C_{d f}, \quad D_{b f c}=D_{b f} \cos (\phi-\theta),
$$

using estimates of the surface and form drag coefficients $C_{d s}$ and $C_{d f}$, the projected area relative to the incident flow angle $A_{b p}$, and the surface areas of the body $A_{b s}$ and wings $A_{w}$. The total force balance along the cable can then be written as

$$
F_{c}=L_{w c}-D_{w c}-D_{b f c}-D_{b s c}-F_{f} \cdot \operatorname{sgn}\left(v_{c}\right),
$$

where $F_{c}$ is the net force acting on the body along the cable and $F_{c f}$ accounts for a sliding friction force always opposing the direction of motion. For a given operating situation, where $\phi, \theta$, and $v_{s}$ are known, the steady-state velocity $v_{c}$ that causes $F_{c}$ to become zero can be determined by combining Eqs. (1) through (7) and using straightforward numerical root finding. It is not necessary to factor in any additional dynamics because we are interested in the steady-state operating point.

Figure $7 \mathrm{~b}$ shows how the estimated performance will vary as a function of the body form drag using a constant wing lift-to-drag ratio. As expected, a lower drag vehicle will be able to obtain higher glide slopes across the range of tow cable angles. The best overall up cable performance approaches a glide slope of 1.5 and is obtained when the cable is vertical. The range of drags evaluated, $0.2-0.8$, accounts for the likely increase in drag for a real vehicle over the idealized simulation shown in Fig. 6 because of the anticipated edges, gaps, roughness, and protrusions that are inevitability present on an operational vehicle. The achievable glide slopes are reduced as the cable becomes angled from vertical and it becomes more difficult for the flyer to move up the cable against the free streamflow. This is analogous to a sailboat sailing closer to the wind with diminished headway. At zero glide slope the curves flatten briefly. At this point the flyer becomes

TABLE 1. Parameter values used in the preliminary modeling.

\begin{tabular}{clc}
\hline \hline Symbol & \multicolumn{1}{c}{ Description } & Values \\
\hline$v_{s}$ & Ship speed & $1-6 \mathrm{kt}$ \\
$F_{c f}$ & Sliding friction & $5-15 \mathrm{~N} \mathrm{~s} \mathrm{~m}^{-1}$ \\
$C_{d f}$ & Body form drag coefficient & $0.1-0.9$ \\
$C_{d s}$ & Body surface friction & $0.006-0.01$ \\
& $\quad$ drag coefficient \\
$A_{b p}$ & Projected frontal \\
& $\quad$ area of the body \\
$A_{w}$ & Total area of the wings & $0.2 \mathrm{~m}^{2}$ \\
$A_{b s}$ & Surface area of the body & $0.20 \mathrm{~m}^{2}$ \\
$C_{l}$ & Wing lift coefficient & $1.5 \mathrm{~m}^{2}$ \\
$\mathrm{LDR}$ & Wing lift-to-drag ratio & $0.5-1.2$ \\
$C_{d}$ & Wing drag coefficient & $2-10$ \\
& & \multicolumn{1}{c}{$C_{l}$} \\
\hline
\end{tabular}



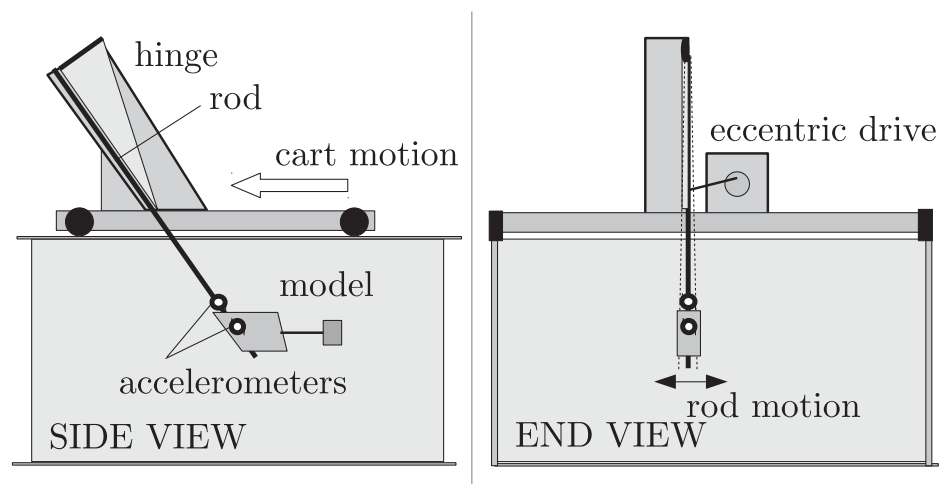

(a) Sketch

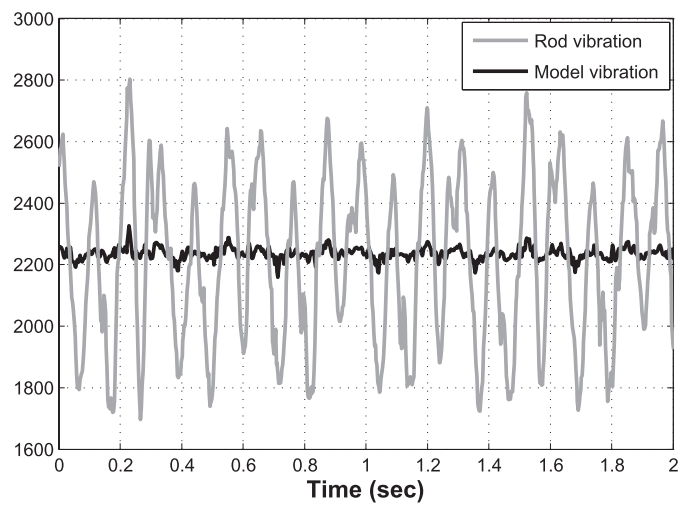

(b) Vibration plot

FIG. 8. (a) Sketch of the tow-tank setup to mimic cable strum. The cart was run down the tank while an eccentric drive motor vibrated a rod pulling the model. (b) A sample vibration data plot showing the reduction in vibrations between the pulling rod and the body.

stuck to the cable because of the along-cable friction force. Beyond this point, at shallower cable angles, the vehicle can no longer make progress up the cable and it is swept backward down the cable, producing a negative glide slope.

\section{Scale model test results}

To evaluate the flyer concept two scale model tests were conducted in a 30 -m-long by 1.5 -m-deep tow tank. The cable strum isolation was tested with a $1 / 3$-scale model pulled by a vibrating rod. The profiling performance was tested using a controllable $1 / 4$-scale model that is able to fly up and down a tight inclined wire. The test results are summarized in the following sections.

\section{a. Vibration testing}

The vibration isolation concepts were tested in a series of tow-tank tests using several different mounting concepts at representative cable vibration frequencies and amplitudes. Figure 8a shows the test rig that was constructed to pull the model through the water using a $0.25^{\prime \prime}$ metal rod. The rod simulated the cable and was intentionally vibrated using an eccentric motor to mimic strum. The amplitude and frequency of vibration could be changed to cover the excursions up to several rod diameters and frequencies between 2 and $10 \mathrm{~Hz}$. In this case the model did not have any wings to create an alongcable (rod) force. Instead, a thin $0.010^{\prime \prime}$ wire was attached to the model just in front of the rod and run parallel several feet up the rod before being tied off. This wire kept the model from being pulled off the rod when it was towed, as the wings would on a full-sized vehicle, but it did not impart any additional stabilizing force to the model. The vibration of the rod was recorded with a small waterproof accelerometer fixed to the rod just above the model. The vibration of the model was recorded with an accelerometer that was fixed inside the model just aft of the rod attachment. Tests were made using tunable versions of the transverse spring assembly and flexible beam attachment mechanisms previously mentioned.

Overall, it was possible to significantly reduce the vibration transmitted to the body due to the tracking stability and effective lateral stiffness of the flyer moving through the water. Figure $8 \mathrm{~b}$ shows a representative reduction of the cable vibration actually measured in the body. Over the range of tests it was relatively straightforward to achieve a tenfold or better reduction in vibration transmitted to the model using both attachment mechanisms. This is an encouraging result and suggests that decoupling the cable strum and vehicle will be possible at full scale.

\section{b. Profiling performance}

To validate the glide slope predictions, tow-tank tests using a $1 / 4$-scale model were completed. Figure 9 shows the test setup and an underwater image taken in the tank during a test. The scale model (Fig. 5b) is a rapidprototyped plastic shell with an internal dry housing containing a high-torque radio-controlled (RC) servo and battery pack. The sweep angle of the model is $30^{\circ}$, meaning the top and bottom of the model are horizontal when the cable angle is $30^{\circ}$ from vertical. This is similar to the view shown in Fig. 6a. The model was ballasted to be slightly heavy, taking $20 \mathrm{~s}$ or more to slide down the cable to the tank bottom between runs. This removed any buoyancy force that would help the model up the cable, thus allowing the wings to be the dominant factor. The RC servo is a closed-loop device with its own internal angle feedback. The servo was controlled wirelessly through the water to move the fins by a computer sending signals via a serial to $\mathrm{RC}$ interface. 


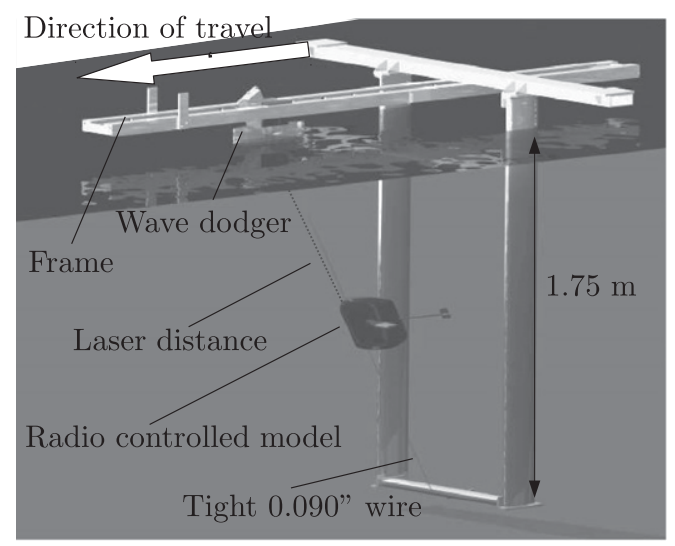

(a)

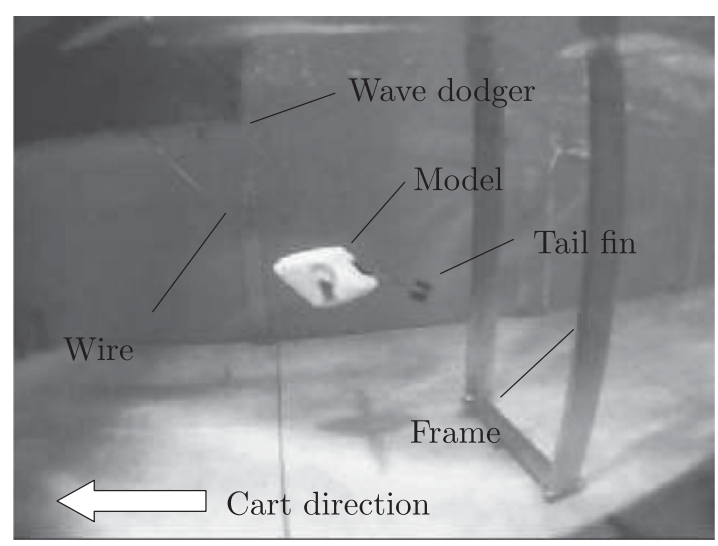

(b)

FIG. 9. (a) CAD drawing of the $1 / 4$-scale tow-tank test rig. The radio-controlled model slides freely on the tight wire stretched between a wave dodger and a frame extending to the bottom of the tow tank. The frame attaches to the bottom of the tow-tank carriage and is driven down the tank at fixed speeds. A standard battery-powered RC servo is used to move the wings on the model. A laser mounted parallel to the wire measures model position along the wire while it is moving. (b) Photo of the model on the test rig taken underwater on a $45^{\circ}$ wire. Note the model is flying up the cable and the tail fin has moved down to align with the apparent flow.

The model slides up and down a tight stainless steel spiral wound wire on low-friction Teflon slides. The wire is pulled between a frame crossbar near the bottom of the tank and a wave dodger just below the water surface. The cable angle is adjustable between vertical and $45^{\circ}$. The slides provide no vibration isolation beyond the clearance in the drilled holes. The wire strum, however, was very small because of the spiral shape of the wire and high tension. The position of the model along the wire is measured using an ASTECH LDM41A laser range finder. The laser is aimed down from the surface along the wire and shot through a tube with a glass end. The tube end is flush with the bottom of the wave dodger. The dodger rides approximately $15 \mathrm{~cm}$ below the surface and ensures that the wake of the tube does not carry bubbles into the path of the laser beam. By using the laser range measurements to record the along-wire position and $\mathrm{RC}$ communications to adjust the wings, no measurement instrumentation requiring an unrepresentative tether was needed in the model. The travel speed of the tow carriage is controlled and recorded using a wheel encoder. The cart can be run up to about $1.5 \mathrm{~m} \mathrm{~s}^{-1}$ and still maintain a clear, wake-free path for the laser. Above this speed, bubbles and the dodger wake would often corrupt the laser data. Overall, this setup allows for testing various tow speeds, wire angles, fin angles, fin shapes, and tail shapes. Approximately 250 test runs were made in total.

Data collection and control were done using the Matlab Simulink environment. During a run down the tank alternating (up-down) wing-angle commands are sent through the radio. The laser measurements were recorded at either 10 or $50 \mathrm{~Hz}$, depending on the specific test run. The $50-\mathrm{Hz}$ data were preferred, but not always possible during the faster runs where the flyer's speed often exceeded the laser tracking rate limit. Practically, this was about $1.5 \mathrm{~m} \mathrm{~s}^{-1}$ for the $50-\mathrm{Hz}$ mode and slightly more for the $10-\mathrm{Hz}$ mode. The laser range accuracy is on the order of $2 \mathrm{~mm}$.

Each test run consisted of alternating the wing angle to specific values and observing the flight of the model as the cart moved down the tank. The wing angles were varied in increments from 0 , defined as horizontal relative to the tank and producing no lift, to $50^{\circ}$ up and $90^{\circ}$ down. Sample data for a single run down the tank containing two climbing segments is shown in Fig. 10a. Different climbing rates were achieved as the wing angles were changed for each run. The trajectory of the model through the water was obtained using the laser measured along the cable distance, the measured cart position, and the wire angle. The glide slopes were then extracted from the steadystate sections of the climbs. Most runs contained two or three climbing sections. At the faster cart speeds, the model was often able to climb the wire within $2 \mathrm{~s}$, and in many cases had not yet reached a steady-state speed.

Test runs were completed using three different cart speeds between 0.65 and $1.4 \mathrm{~m} \mathrm{~s}^{-1}$, two different wings with aspect ratios of 3-1 and 4-1, two tails 20 and $30 \mathrm{~cm}$ in length, and cable angles of $75^{\circ}, 60^{\circ}$, and $45^{\circ}$. Tests for the upward-climbing and down-cable performance were done separately because of the approximately $90^{\circ}$ travel limit of the RC servo. Figures 10-13 summarize the results. Cart runs that had obvious problems, such as poor 
(a)

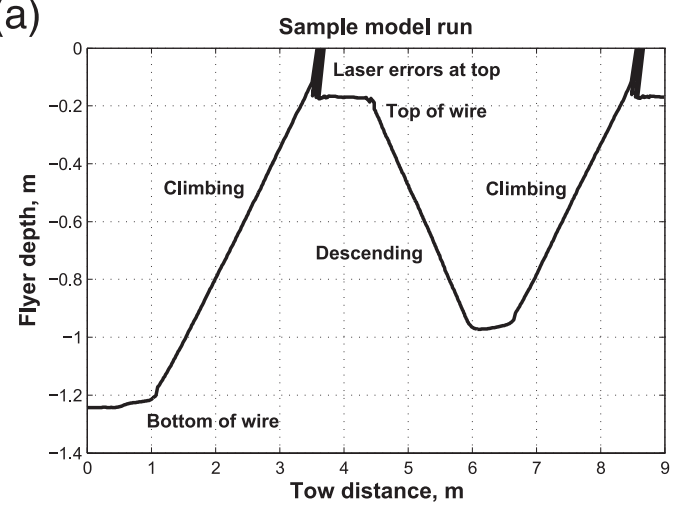

(b)

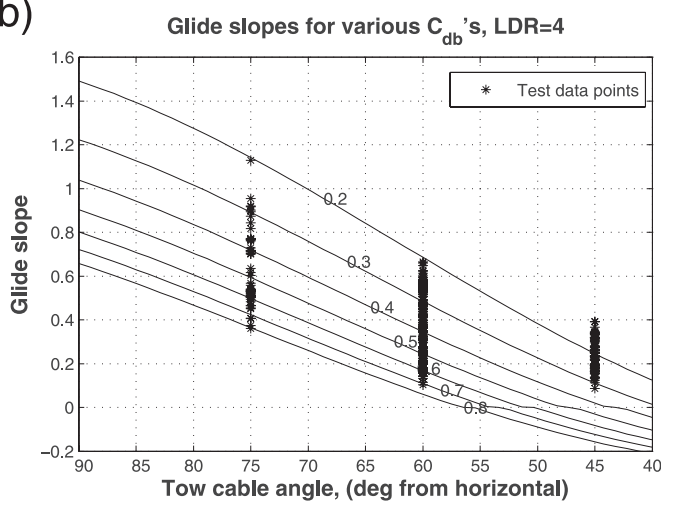

(c)

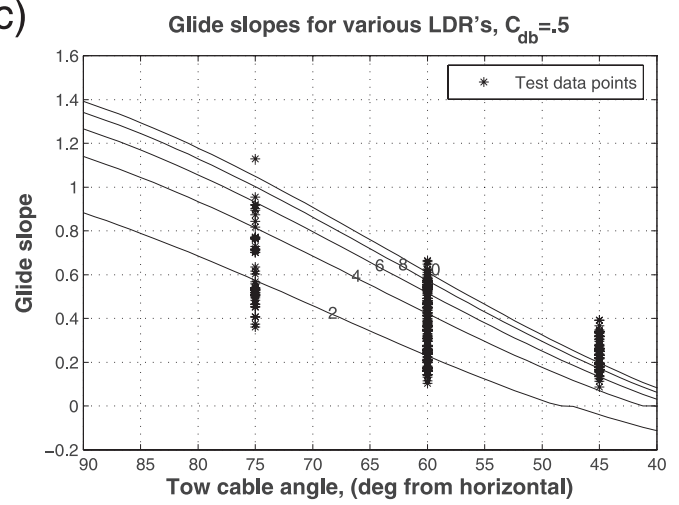

FIG. 10. Summary of the scale tow tests. (a) A sample run down the tow tank where the wing angles alternate between climb and descent. The glide slope results were extracted from the steady-state slope values on the climbing portions of the track. (b),(c) All of the test data points showing the achieved glide slopes at wire angles of $75^{\circ}, 60^{\circ}$, and $45^{\circ}$ overlaid on the estimated performance plots for the scale model. Note the $75^{\circ}$ results likely underpredict the performance resulting from tracking limitations at high model speeds.

laser tracking, potential communications hang-ups to the RC servo, or very short sections of steady-state behavior, have been removed from the data presented here. This was not generally an issue except for the $75^{\circ}$ wire results where the model was able to outpace the $10-\mathrm{Hz}$ laser tracking at the higher cart speeds.

The complete set of test results for the three cable angles are shown overlaid on the initial predictions in Fig. 10. Overall, the complete set of tests, encompassing all of the varying configurations, is consistent with the initial predictions. The general decrease in glide slope performance for decreasing cable angles is seen and the range of data overlaps nicely with the anticipated bounds. The majority of glide slope variation in these figures is caused by varying the wing angle in the tests. Smaller wing angles produced the lower glide slopes and larger wing angles were able to achieve the peak values.

Figure 11 shows the detailed plots for the various tests of a $60^{\circ}$ wire as a function of wing angle. The data range extends from tipping the wings slightly up $10^{\circ}$ to approximately $40^{\circ}$. At angles beyond this point, the model was not able to climb up the wire because of wing stalling.
The best results were obtained using faster cart speeds and the higher aspect ratio wings. This is likely due to overcoming some friction along the wire and the greater lift to drag ratio of the higher aspect ratio wings. Two different tail fins, a 30-cm-long fin with small vanes and a shorter 20-cm-long fin with larger vanes, were also tried. Although both fins allowed the model to maintain a steady orientation to the flow while being pulled, the results did not clearly indicated which fin option is better.

Results for the $45^{\circ}$ cable are shown in Fig. 12. As anticipated the achievable glide slopes were not as steep at this angle. The range of effective fin angles was also smaller, indicating it was easier to stall the wings. Given that no appreciable performance change was noticed for the different tail fins on the $60^{\circ}$ wire, these tests were done primarily with the shorter tail fin. Additionally, the shorter fin tended to turn down and align with the flow more quickly than the long fin, allowing for longer steadystate sections of motion along the wire.

Separate tests for the downward motion of the flyer were also completed using various downward wing angles. These tests, shown in Fig. 13, indicate an optimal 
(a)

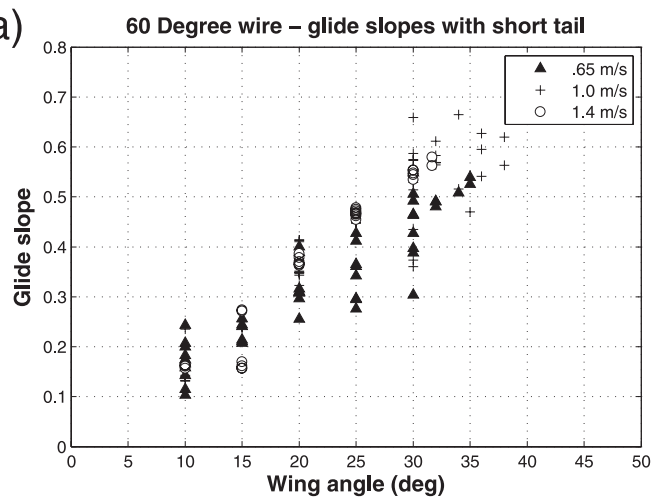

(b)

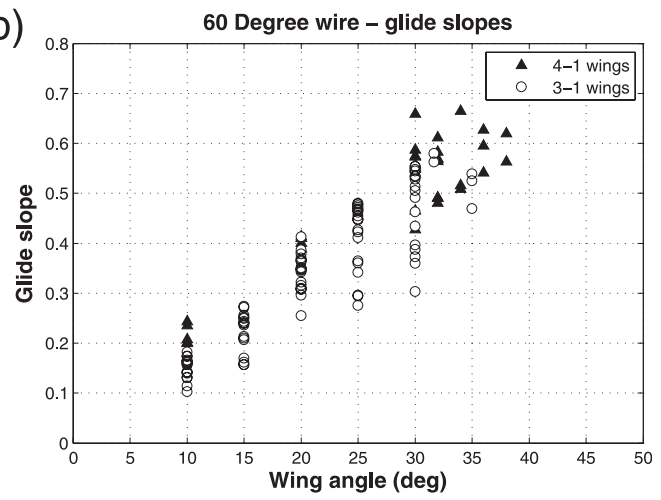

(c)

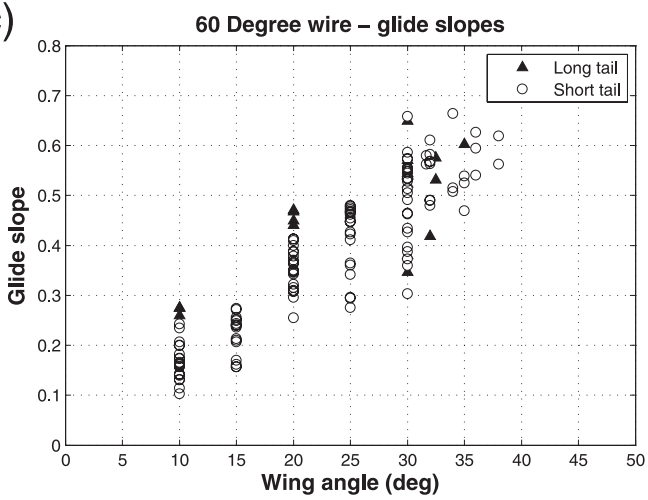

FIG. 11. Summary plots for a $60^{\circ}$ wire and a range of wing angles. (a) Glides slopes achieved at various cart speeds.

(b) Glide slopes for two different aspect ratio wings. (c) Glide slopes for two different tail fins.

wing angle for moving down the cable. For both the $60^{\circ}$ and $45^{\circ}$ wire angles the maximum downward glide slope was achieved at wing angles between $60^{\circ}$ and $70^{\circ}$ down. At these angles the wings were generating some useful force to fly down the cable. Overall, the downward glide slopes can be greater than 1.0, and are the reason the asymmetric pattern is shown for the actual vehicle trajectory in Fig. 2.

\section{c. Test limitations}

Although the scale model tests were successful and confirmed the wire flyer concept, there are several limitations. The scale rig was too small to fully develop a test for demonstrating optimal wing performance or behaviors like constant-depth flying and finescale profiling. The dynamics of the scale model were quite fast and most climbs took a few seconds or less. With a $10-\mathrm{Hz}$ sampling rate on the laser position and the computer-to-RC interface it was not possible to close the loop with a wingangle controller. Because we could not directly control the angle of attack, we relied on the model reaching a steady-state angle of attack for each commanded wing angle. The limited vertical extent of travel and problems with high-speed sampling also made it difficult to completely test the $75^{\circ}$ cable angle. The presented results likely underpredict the $75^{\circ}$ performance and we did not try to complete tests using a purely vertical wire.

Additionally, these tests were designed to separately address the issues of cable strum and glide slope performance. The cable strum tests pulled the flyer model at a constant depth only using a vibrating $0.25^{\prime \prime}$ steel rod. The glide slope tests used a much smaller diameter $0.090^{\prime \prime}$ spiral wound wire under high tension to minimize strum. Although each test was instructive, building a representative combined test to directly investigate the effect of model vibration on the glide slopes at $1 / 4$ scale would be very challenging. The fast dynamics of the lightweight model would make the associated high-speed measurements difficult without including more instrumentation in the model. Additionally, properly scaling the tension, stiffness, and masses that govern cable dynamics would be extremely difficult over a useful range of operating conditions. Even for the current $1 / 4$-scale tests, the maximum cart speed of $1.5 \mathrm{~m} \mathrm{~s}^{-1}$ is below the appropriate Reynolds scaling. To properly scale a full-sized vehicle traveling between 1 and $5 \mathrm{kt}$, the maximum cart speed would need to be $10 \mathrm{~m} \mathrm{~s}^{-1}$. This would cause the vehicle to climb the test wire in $0.2 \mathrm{~s}$. At such a speed it would be intractable to measure steady-state motion between the travel limits on the test rig. Because of the surface roughness and 
(a)

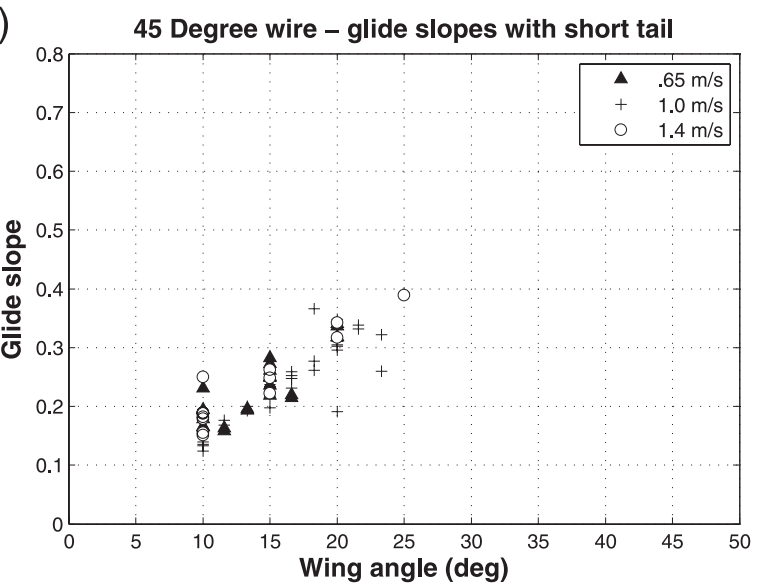

(b)

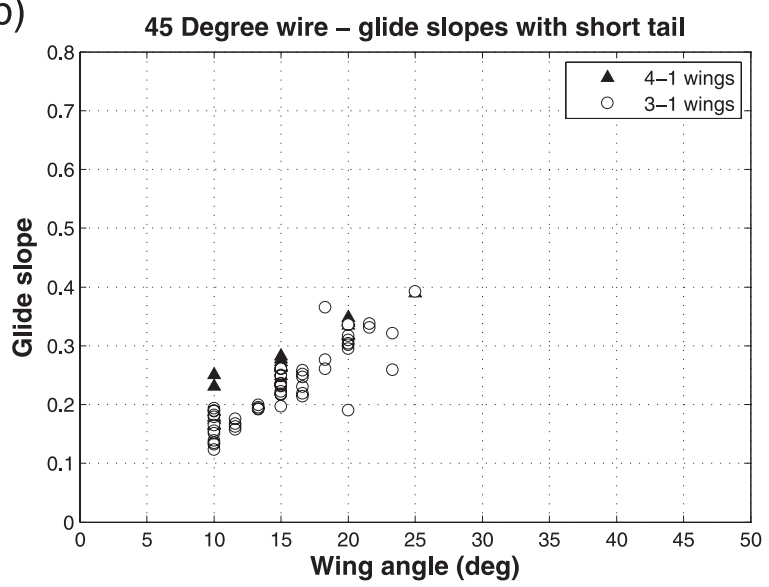

FIG. 12. Test results similar to those shown in Fig. 11 for a $45^{\circ}$ cable.

leading edge seam on the model, the tests should be, however, within the turbulent flow regime the full-sized vehicle is expected to encounter. In this situation the profile drag coefficient is not a direct function of Reynolds number and the tests should have validity for predicting the glide slope performance of the full-sized vehicle.

\section{Conclusions}

This paper has outlined the design concept for a new wire flying profiling vehicle and presented initial scale model test results that validate the concept. The vehicle is motivated by a desire to obtain high horizontal profile resolution for a variety of oceanographic studies over full ocean depth. Current profiling solutions, such as undulating tow bodies, are in general limited to the upper $500 \mathrm{~m}$ of the water column and obtain glide slopes of 0.33 or less over typical towing speeds and configurations. Alternatively, moving vessel profilers can provide repeated vertical profiles but are limited by their

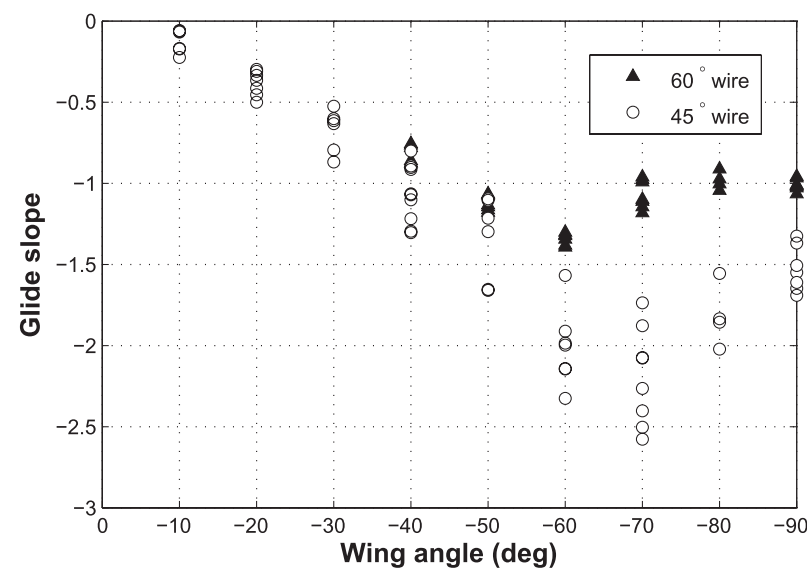

FIG. 13. Down-wire glides slope tests for $60^{\circ}$ and $45^{\circ}$ wire angles.

cycle time and recovery to the surface, which effectively limits the spacing between casts at a given ship speed. Scale model test results for the wire flying vehicle indicate upward glide slopes approaching 1.0 and downward glide slopes greater than 2.0 for cable angles typical of ship speeds between 2 and $6 \mathrm{kt}$. These results meet our initial design objective to achieve glides slopes between 0.3 and 1.0 for steady-state vertical motion, and may in fact be conservative predictions of the performance resulting from the limited range of the tow-tank test rig. The controllable wings will allow user-defined profiling rates up to $3.0 \mathrm{~m} \mathrm{~s}^{-1}$ over sections of the tow cable with angles generally steeper than $45^{\circ}$. In many situations this would offer a fourfold increase in horizontal profiling resolution over current systems and an operating range over the whole water column. The system will also inherently decouple ship heave from the vehicle, helping to create smoother profiles and reduce related errors. From an operational perspective, the system will be able to cover any part of the water column and be used in conjunction with other sensors, such as deeptow side-scan systems. The next phase of this work is to construct a 1000-m rated prototype vehicle that can carry numerous standard oceanographic sensors. This system will be tested first on a static vertical wire as a moored profiler and then from a ship. The first test cruise will be at the shelfbreak front south of Block Island, Rhode Island. Data will be collected with the presented cable flying system, SeaSoar and an Oceanscience Underway CTD to make a comparative analysis of the data density and profiling capabilities.

Acknowledgments. This work was funded by NSF Grant 0728600 and is continuing under Grant 0968947. The authors thank Todd Gregory, Matt Jewell, Brian Amaral, and Edward Richards who helped build the tow-tank test setup and run the experiments. 


\section{REFERENCES}

Abbott, I., and A. Doenhoff, 1959: Theory of Wing Sections. Dover Publications, $693 \mathrm{pp}$.

Allen, V., J. Cornell, M. Moore, N. Crisp, and J. Dunning, 2002: Operational oceanography using the 'new' SeaSoar ocean undulator. Sea Technol., April 2002.

Baker, E., and H. B. Milburn, 1997: MAPR: A new instrument for hydrothermal plume mapping. Ridge Events, 8, 23-25.

_ , and C. German, 2004: On the global distribution of hydrothermal vent fields. Mid-Ocean Ridges: Hydrothermal Interactions between the Lithosphere and Oceans, Geophys. Monogr., Vol. 148, Amer. Geophys. Union, 245-266.

Blevins, R., 1977: Flow-Induced Vibrations. Van Nostrand Reinhold Company, 363 pp.

Brewer, P., and T. Moore, Eds., 2001: Ocean Sciences at the New Millennium. University Corporation for Atmospheric Research, $152 \mathrm{pp}$.

Crawford, W., 1986: A comparison of length scales and decay times of turbulence in stably stratified flows. J. Phys. Oceanogr., 16, 1847-1854.

D'Asaro, E., S. Walker, and E. Baker, 1994: Structure of two hydrothermal megaplumes. J. Geophys., Res., 99 (C10), $20361-$ 20373.

Dickey, T. D., E. C. Itsweire, M. Moline, and M. J. Perry, 2008: Introduction to the Limnology and Oceanography special issue on Autonomous and Lagrangian Platforms and Sensors (ALPS). Limnol. Oceanogr., 53, 2057-2061.

Dillon, T., 1982: Vertical overturns: A comparison of Thorpe and Ozmidov scales. J. Geophys. Res., 87, 9601-9613.

Doherty, K. W., D. E. Frye, S. P. Liberatore, and J. M. Toole, 1999: A moored profiling instrument. J. Atmos. Oceanic Technol., 16, 1816-1829.

Eriksen, C., T. Osse, R. Light, T. Wen, T. Lehman, P. Sabin, J. Ballard, and A. Chiodi, 2001: Seaglider: A long-range autonomous underwater vehicle for oceanographic research. IEEE J. Oceanic Eng., 26, 424-436, doi:10.1109/48.972073.

Fowler, G. A., J. M. Hamilton, B. D. Beanlands, and A. R. Furlong, 1997: A wave-powered profiler for long-term monitoring. Oceans '97 MTS/IEEE Conf. Proc., Halifax, NS, Canada, IEEE, 225-228.

Furlong, A., J. Osler, H. Christian, D. Cunningham, and S. Pecknold, 2006: The Moving Vessel Profiler (MVP)—A rapid environmental assessment tool for the collection of water column profiles and sediment classifications. Defense Research and Development Canada, 13 pp. [Available online at http:// cradpdf.drdc-rddc.gc.ca/PDFS/unc59/p527475.pdf.]
German, C., K. Richards, M. Rudnicki, M. Lam, and J. Charlou, 1998: Topographic control of a dispersing hydrothermal plume. Earth Planet. Sci. Lett., 156, 267-273.

—- D. Yoerger, M. Jakuba, T. Shank, C. Langmuir, and K. Nakamura, 2008: Hydrothermal exploration with the Autonomous Benthic Explorer. Deep-Sea Res. I, 55, 203-219, doi:10.1016/j.dsr.2007.11.004.

Gobat, J., and M. Grosenbaugh, 2000: WHOI Cable v2.0: Time Domain Numerical Simulation of Moored and Towed Oceanographic Systems. Woods Hole Oceanographic Institution Tech. Rep. WHOI-2000-08, 85 pp.

Herman, A. W., B. Beanlands, M. Chin-Yee, A. Furlong, J. Snow, S. Young, and T. Phillips, 1998: The Moving Vessel Profiler (MVP): In-situ sampling of plankton and physical parameters at $12 \mathrm{kts}$ and the integration of a new laser/optical plankton counter. Proc. Oceanology Int., Vol. 102, Brighton, United Kingdom, 123-135.

Kinsey, J. C., R. M. Eustice, and L. L. Whitcomb, 2006: A survey of underwater vehicle navigation: Recent advances and new challenges. IFAC Conf. Maneuvering and Control of Marine Craft, Lisbon, Portugal, IFAC, 1-12.

Klymak, J., and J. Moum, 2007: Oceanic isopycnal slope spectra. Part II: Turbulence. J. Phys. Oceanogr., 37, 1232-1245.

Langmuir, C., C. German, P. Michael, D. Yoerger, D. Fornari, T. Shank, P. Asimow, and H. Edmonds, 2004: Hydrothermal prospecting and petrological sampling in the Lau Basin: Background data for the integrated study site. Eos, Trans. Amer. Geophys. Union, 85, Abstract B13A-0189.

Morrison, T., III, J. D. Billings, K. W. Doherty, and J. M. Toole, 2000: The McLane moored profiler: A platform for physical, biological, and chemical oceanographic measurements. Proc. Oceanology Int. 2000 Conf., 1-18.

Polzin, K., J. Toole, J. Ledwell, and R. Schmitt, 1997: Spatial variability of turbulent mixing in the abyssal ocean. Science, 276, 93-96.

Rudnick, D. L., and J. Klinke, 2007: The Underway Conductivity Temperature Depth instrument. J. Atmos. Oceanic Technol., 24, 1910-1923.

Sellschopp, J., 1997: A towed CTD chain for two dimensional high resolution hydrography. Deep-Sea Res. I, 44, 147-165, doi:10.1016/S0967-0637(96)00087-8.

Ullman, D. S., A. C. Dale, D. Hebert, and J. D. Barth, 2003: The front on the Northern Flank of Georges Bank in spring: 2. Cross-frontal fluxes and mixing. J. Geophys. Res., 108, 8010, doi:10.1029/2002JC001328.

Webb, D. C., P. J. Simonetti, and C. P. Jones, 2001: SLOCUM: An underwater glider propelled by environmental energy. IEEE J. Oceanic Eng., 26, 447-452. 